\title{
Proactive use of PROMs in ovarian cancer survivors: a systematic review
}

\author{
Anette Stolberg Kargo ${ }^{1,2,3^{*}}$ B. Angela Coulter ${ }^{2,3}$, Pernille Tine Jensen ${ }^{4,5}$ and Karina Dahl Steffensen ${ }^{1,2,3}$
}

\begin{abstract}
Introduction: The use of patient reported outcome measures (PROMs) has increased during the past decade, and the focus on how to use them has resulted in a more proactive application. Studies have shown that proactive use of PROMs during treatment improves patient-clinician communication, leads to better symptom management and may prolong survival among advanced cancer patients. Ovarian cancer is a serious disease in which the majority of patients experience recurrence during the follow-up period and suffer from a number of severe symptoms from underlying disease. This systematic review was conducted to assess the evidence on the proactive use of PROMs as a dialogue tool during follow-up of ovarian cancer patients.

Results: The following databases were searched for relevant literature; PubMed, EMBASE, CINAHL, and the Cochrane Library. The search was conducted in April 2019 without any filters or limits. A total of 643 publications were identified, and 48 studies were found to be potentially eligible. Of the 48 papers, none met the final inclusion criterion of using PROMs proactively as a dialogue tool for ovarian cancer patients during follow-up.

Conclusion: Studies have shown that PROMs can identify otherwise undetected symptoms. Using PROMs proactively during the consultation has been shown to improve symptom management for patients with some other types of cancer. However, we found no studies that had examined the proactive use of PROMs during followup of ovarian cancer patients. Future studies should evaluate if the proactive use of PROMs could facilitate a more individualized and more effective follow-up program tailored to the ovarian cancer patient's needs and preferences.
\end{abstract}

Keywords: Ovarian cancer, Follow-up, Patient reported outcome, Quality of life

\section{Introduction}

Worldwide, every year 240,000 women are diagnosed with fallopian tube, primary peritoneal, or ovarian cancer (OC), often in advanced stage with approximately 152, 000 dying from the disease. This makes OC the leading cause of gynecological cancer-related deaths. Generally, the initial treatment is extensive surgery and chemotherapy to which most patients respond well. Nevertheless, about $80 \%$ of these tumors will recur within a few years after primary treatment and treatment of recurrence is rarely curative [1].

After treatment, most patients enter a five-year followup (FU) program, including routine clinical visits,

\footnotetext{
* Correspondence: Anette.Stolberg.Kargo@rsyd.dk

'Department of Clinical Oncology, Sygehus Lillebalt, Vejle Sygehus, Beriderbakken 4, DK-7100 Vejle, Denmark

${ }^{2}$ Institute of Regional Health Research, University of Southern Denmark, Winsløwparken 19, 3, 5000 Odense, Denmark

Full list of author information is available at the end of the article
}

imaging, physical examination, and measurement of the cancer biomarker CA125. The primary purpose of FU is early detection of recurrence, but there is no evidence that routine FU increases survival [2]. It may provide reassurance, but for some routine FU may induce anxiety and fear of recurrence [3]. The literature is sparse on this matter in $\mathrm{OC}$ patients which further highlights the need for research on individualized follow up plans based on patient needs and preferences [3, 4].

Patient Reported Outcome Measures (PROMs) are defined as "any report of the status of a patient's health condition that comes directly from the patient, without interpretation of the patient's response by a clinician or anyone else". Patient reported outcomes can be measured by means of standardized and validated questionnaires designed for self-completion by patients or by interview [5]. There are several types of PROMs; generic and disease-specific. Generic PROMs are designed to collect data across disease groups, whereas disease- 
specific PROMs are designed to collect data on outcomes of specific conditions or diagnoses [6]. Some PROMs combine generic and disease-specific elements to capture a broad assessment of the patient's health status. PROMs can be used to obtain information on physical, emotional, social, sexual, and cognitive functioning besides evaluating side effects or late effects, global health status, and quality of life (QoL). They are often used in clinical trials to monitor health status and QoL before, during, and after treatments to measure patientrelated, subjective outcomes secondary to primary endpoints such as survival.

During the past decade, there has been increased interest in using PROMs in routine practice to monitor patient symptoms during treatment. Their use for clarifying patient needs and monitoring late side effects in long-term survivors has received less attention [7]. Evidence from various cancer diagnoses suggests that the use of PROMs during a clinical visit may improve clinician-patient communication by focusing on issues of greater concern to the patient without prolonging the visit [8]. There is also evidence that clinicians often underestimate late side-effects $[9,10]$. Use of PROMs as a dialogue tool, alongside blood samples and imaging, may provide clinicians with more valid and comprehensive knowledge of the patient's problems [11]. A recent study suggested that active use of PROMs during advanced cancer treatment may even prolong survival [12].

We were specifically interested in the potential use of PROMs to improve follow-up care for ovarian cancer survivors. We therefore undertook a systematic review to determine what is already known about proactive use of PROMs as a dialogue tool during follow-up of these patients.

\section{Methods}

\section{Data sources and search strategy}

We conducted a systematic review to assess the proactive use of PROMs as a dialog or screening tool during followup of patients after completion of active treatment (e.g. surgery and chemotherapy) for OC. The review was conducted according to Preferred Reporting Items for Systematic Reviews and Meta-analyses (PRISMA) [13, 14].

During April 2019 a systematic search was conducted by author AK searching the following databases: PubMed, CINAHL, EMBASE, and the Cochrane Library. Relevant articles published between 1974 to April 2019 were identified. Search strategy in PubMed combining Mesh term "Ovarian Neoplasms", "Patient Reported Outcome Measures", "Patient Outcome Assessment", "Health Care Surveys" and key words "Ovarian Cancer", "ovarian neoplasms", "patient outcome assessment" and "patient reported outcome".

The search terms derived after advice from a research librarian and an advisory group including all co-authors who also helped identify additional "grey literature" of relevance to the research question. No filters were applied. The search strategy for databases PubMed, EMBASE, CINAHL and The Cochrane Library is available in Additional file 1. Titles and abstracts of studies retrieved from the search were screened by AK. Reference lists were manually screened to identify additional papers.

\section{Study selection}

Articles were considered eligible if the study participants were $\mathrm{OC}$ patients and the proactive use of one or more PROMs during FU was involved. Proactive use of a PROM is defined as data reported by a patient, presented to the clinical staff, and used actively during the consultation as a dialogue tool between patient and clinician.

Studies describing the development of PROMs or PROMs used as a primary or secondary outcome in clinical trials were excluded. Studies were also excluded if PROMs were used to assess the eligibility of patients for chemotherapy, or if they were used to retrospectively identify coping strategies or late side effects with no proactive use.

Review papers were examined for potentially eligible studies that might have been missed in the search strategy. Studies involving multiple cancer sites were excluded if data on OC were not presented separately.

\section{Identification of relevant articles}

The titles and abstracts of all retrieved papers were evaluated to determine the relevance of the study. Full texts were retrieved and examined in case the abstract alone did not provide sufficient information.

\section{Data extraction}

All potentially eligible studies were screened by reviewer AK. Data were extracted on publication details (author, year and country of study, study design, intervention, and sample size) and all PROM-specific data (type of PROM, how and when used) were entered into a predesigned form.

\section{Results}

The search led to the identification of 643 studies, and after removal of duplicates a total of 337 abstracts were selected for detailed examination (Fig. 1). Forty-eight titles/ abstracts met the initial selection criteria and full texts of these were obtained for the assessment of eligibility.

Data extraction was performed on the 48 potentially eligible studies, none of which met the final inclusion criterion of using PROMs proactively as a dialogue tool in the follow-up care of OC patients. These papers were excluded for the following reasons: literature review on the use of PROMs $(n=10)$; description of PROM development, papers showing OC data combined with other 


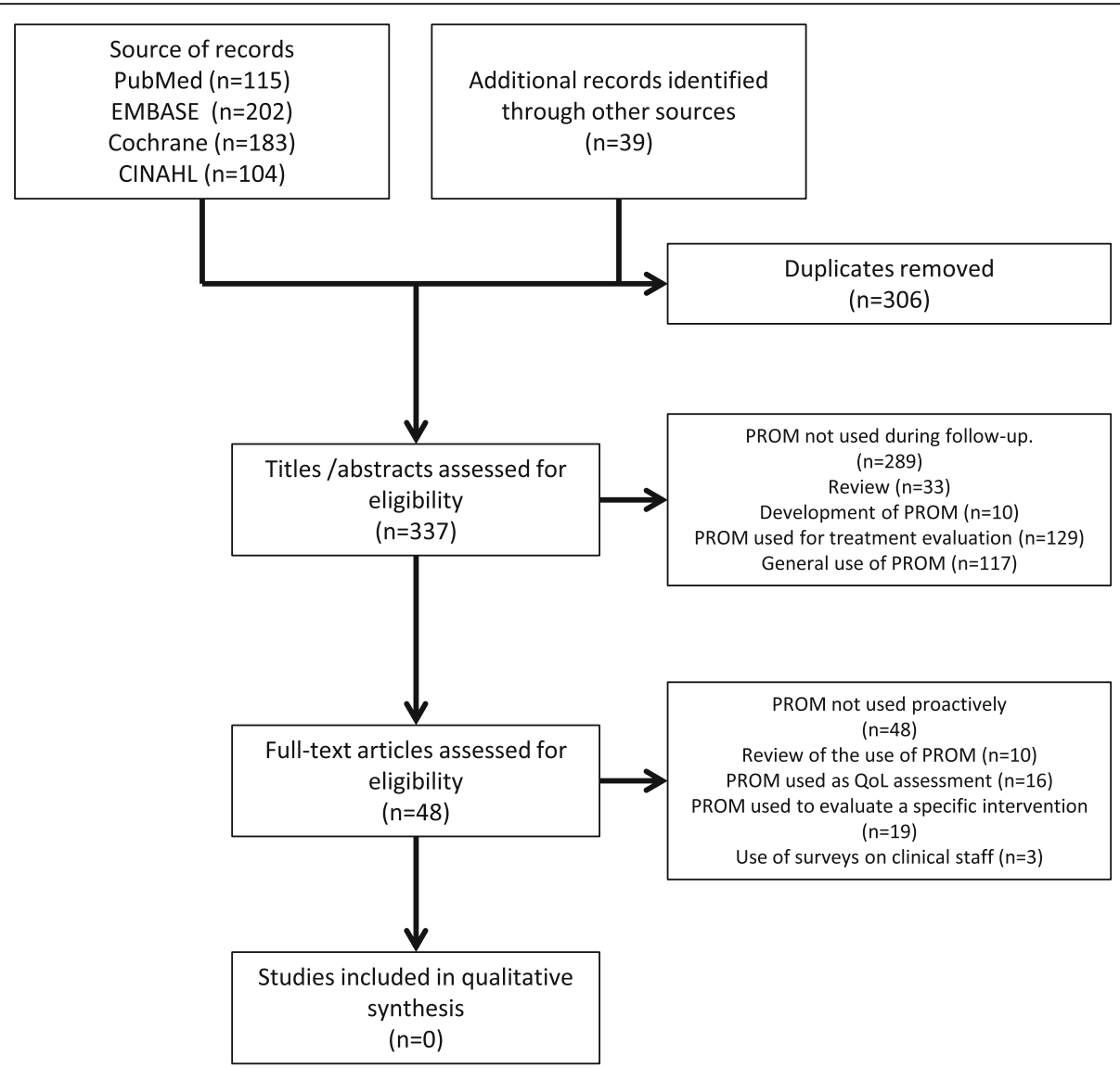

Fig. 1 Flow diagram for search and selection process

cancers, and PROMs used to evaluate a specific intervention $(n=19)$; surveys investigating clinical staff's opinion regarding the use of PROMs $(n=3)$; studies where PROMs were used to assess the patient's perspective on QoL, or for obtaining prognostic information on life expectancy where the data collected were not used proactively in the care of individual patients $(n=16)$. The search and selection process is shown in Fig. 1. Characteristics of the studies and reason for exclusion are summarized in Table 1.

We found no studies that proactively used PROMs during follow-up care after ovarian cancer treatment and therefore no qualitative synthesis was applied.

\section{Discussion}

We searched for studies involving the proactive use of PROMs during follow-up after ovarian cancer treatment but found none. Most studies identified were trials evaluating the effect of specific interventions of OC. PROMs have traditionally been used in observational studies and clinical trials to measure the long-term effect of an intervention or to capture toxicity of new therapies. For some other types of cancer the application of PROMs is progressing from being purely a research tool to monitor side effects in clinical trials, to being used proactively in clinical practice for monitoring symptoms during treatment. By incorporating patients' assessments and priorities in care management it has revealed a higher frequency of unmet needs that otherwise might have been un-recognized $[3,10,61]$.However, we found no evidence that this application of PROMs has been tested with OC patients.

de Rooij et al. performed a randomized trial aiming to assess long-term impact of an automatically generated Survivorship Care Plan (SCP) in ovarian cancer patients. The author found that ovarian cancer patients provided with a SCP did not report increased satisfaction with information provision or care [45]. This highlights that optimal follow up plans should be individualized and tailored for each patient and not a automatically predefined tool for all patients.

A recent study has shown that pro-active use of PROMs during treatment improves the QoL of cancer patients [56]. Detmar et al. conducted a randomized clinical trial with patients receiving palliative chemotherapy for different cancer types. Incorporating PROM assessments into clinical practice during treatment and actively using them during the consultation improved 
Table 1 Characteristics of studies and reasons for exclusion

\begin{tabular}{ll}
\hline Study & Aim and reason for exclusion \\
\hline Velikova G et al. 2004 [10] & $\begin{array}{l}\text { Evaluated the effectiveness of active use of a PROM during treatment and the effect on QoL. This study was } \\
\text { performed on mixed cancer sites and data on OC patients were not reported separately. PROMs were primarily } \\
\text { used during active treatment. }\end{array}$
\end{tabular}

Hess LM et al. 2012 [15] R Review assessed published literature regarding Health Related QoL among ovarian cancer patients. Reported no studies using PROMs actively during FU.

Hilpert F et al. 2018 [16] Review examined the current status regard the use of PROM in clinical trials. Highlight that PROM has potential to be used in decision making. Find that PROM most likely will become more important in clinical trials.

Wiering B et al. $2017[17]$

Review assessed the extent to which patients were involved in the development of PROMs and if patients involvement has increased over time. They reported no studies using PROMs actively over time.

Preston $\mathrm{N}$ et al. 2015 [18]

Review assessed different PROMs used in gynecological oncology in order to identify the most appropriate PROM. No studies reported using PROMs actively during FU.

Clarke T et al. 2014 [19]

Review compared the benefits of different follow-up strategies in patients with OC. Found one randomized controlled trail regarding follow-up strategies. Highlights the needs for new trails aiming to investigate in different types of FU. Found no study that used PROMs actively.

Kew F et al. 2011 [20]

Review compared the potential benefits of different follow-up strategies in OC survivors. Highlights the needs for trails comparing different FU programs with focus on QoL, survival and cost. Found no studies using PROMs during FU.

Zikos et al. 2016 [21]

Review assessed whether Health Related QoL could provide prognostic information among OC survivors. No studies used PROMs actively during FU.

Ahmed-Lecheheb et al. 2016 [22] Review examined the literature measuring QoL in patients who survived OC. Find that OC survivors experience a wide range of sequelae that have a negative impact on QoL. Found no studies using PROMs actively.

Detmar SB et al. 2002 [23]

Examined the effect of using PROMs on communications between clinician and patients during active palliative treatment. This study was performed on mixed cancer sites. Study excluded because PROMs were used during treatment and data on OC patients were not reported separately.

King MT et al. 2018 [24]

Aimed to review and validate MOST, a new PROM for OC patients with relapse. PROM used during treatment. MOST can be used to measure symptom benefit and burden during treatment. PROM were not used during FU.

McCorkle R et al. 2011 [25]

Evaluated the effect of support for self-management; the patients were included shortly after surgery and the intervention was applied during active treatment. The intervention was not offered during FU.

Meraner V et al. 2012 [26]

Assessed the course of depressive symptoms, anxiety, fatigue and QoL in patients with OC over the course of chemotherapy and for the 2 first aftercare visits. PROMs were used during treatment and it is unclear if PROMs was used actively and the study was therefore excluded.

Beesley VL et al. 2013 [27]

Aimed to identify risk factors for future unmet needs after first-line treatment for OC. PROMs were used during FU, but the pro-actively use of PROMs is unclear and the study was excluded.

Stewart DE et al. 2001 [28]

Study designed to learn more about self-management of physical health and QoL of OC survivors. Participants had been at least 2 years without treatment. PROMs were used anonymously and not used actively.

Bodurka-Bevers D et al. 2000 [29] Assessed the prevalence of anxiety and depressive symptoms and QoL problems in OC patients. PROMs were not used proactively.

Greimel E et al. 2011 [30]

Aimed to compare QoL in long-term OC survivors with short-term survivors. PROMs were not used proactively.

Liavaag AH et al. 2007 [31]

Aimed to explore fatigue, QoL, and somatic and mental morbidity between $\mathrm{OC}$ with and without relapse. PROMs were not used actively.

Matei D et al. 2009 [32]

Compared late effects of treatment on physical well-being between OGCT survivors and matched controls. PROMs were not used proactively.

Mercieca-Bebber RL et al. 2017 [33] Investigated if low QoL among OC survivors was associated with earlier study drop out. PROMs were used during FU, but were not used actively.

Guidozzi F. 1993 [34]

Interviewed OC survivors regarding the impact of OC on their QoL. How the answers were used is unclear and the study was removed.

Chase DM et al. 2011 [35]

This paper is an overview of the state of the science of QoL measurement in clinical management. Found no studies using PROMs actively.

Williams LA et al. 2013 [36]

Aimed to develop a new questionnaire for OC patients. Patients were involved in the development of a questionnaire. Their response was not used proactively.

Greimel E et al. 2003 [37]

Aimed to validate the EORTC QLQ-OV28 disease-specific questionnaire. PROMs were not used actively.

Snyder CF et al. 2009 [38]

Focus on implementing PROMs in the clinical setting in general, and not on using PROMs proactively.

Bördlein-Wahl l et al. 2009 [39]

Described the general knowledge of PROMs from a clinician, patient, and scientist point of view. PROMs were not used actively. 
Table 1 Characteristics of studies and reasons for exclusion (Continued)

\begin{tabular}{|c|c|}
\hline Study & Aim and reason for exclusion \\
\hline Roncolato FT et al. 2017 [40] & $\begin{array}{l}\text { Investigated whether baseline QoL score would be prognostic. PROMs were used to assess the effect of an } \\
\text { intervention but not used proactively. }\end{array}$ \\
\hline Jensen RE et al. 2016 [41] & $\begin{array}{l}\text { Accompanies the editorial of E. Basch et al. [42]. PROMs were used to detect change in QoL score and to } \\
\text { optimize symptom management during active treatment. }\end{array}$ \\
\hline Du Bois A et al. 2005 [43] & $\begin{array}{l}\text { Aimed to evaluate if standard care guidelines were followed among OC patients. Surveys were used in clinicians } \\
\text { and not OC patients. }\end{array}$ \\
\hline Madalinska JB et al. 2007 [44] & Aimed to investigate if baseline characteristic can predict surgery outcome. PROMs were not used proactively. \\
\hline De Rooij BH et al. 2017 [45] & $\begin{array}{l}\text { Aimed to assess the effect of survivorship care plans. PROMs were used during FU but were not used } \\
\text { proactively. }\end{array}$ \\
\hline Phillips KA et al. 2004 [46] & $\begin{array}{l}\text { Used PROMs to investigate if gatekeeper requirements are associated with the utilization of cancer screening, } \\
\text { not specific OC patients. PROMs were not used pro-actively. }\end{array}$ \\
\hline Beesley VL et al. 2018 [42] & $\begin{array}{l}\text { Aimed to identify coping strategies, used by OC survivors. PROM were used to assess their QoL but not used } \\
\text { proactively. }\end{array}$ \\
\hline Cesario SK et al. 2010 [47] & $\begin{array}{l}\text { Aimed to identify OC patients' worries and fears. PROMs were collected among OC survivors once and not used } \\
\text { proactively. }\end{array}$ \\
\hline Keim-Malpass J et al. 2017 [48] & PROMs used to identify physical and psychosocial problems at different time points during treatment. \\
\hline Oberguggenberger A et al. 2016 [49] & PROMs used to identify physical problems after genetic BRCA testing. PROMs were not used actively. \\
\hline Stukenborg GJ et al. 2016 [50] & $\begin{array}{l}\text { Score of PROMs were used to estimate if patients should be given palliative or more aggressive treatment. This } \\
\text { study was performed on mixed cancer sites. Data on OC patients were not reported separately. }\end{array}$ \\
\hline Rietveld M et al. 2016 [51] & $\begin{array}{l}\text { PROMs used to measure the satisfaction with information provided at the time of diagnosis. PROMs were not } \\
\text { used pro-actively. }\end{array}$ \\
\hline Beesley VL et al. 2011 [52] & PROMs used to identify the amount of physical activity after diagnosis of OC. PROMs were not used proactively. \\
\hline Greimel E et al. 2019 [53] & $\begin{array}{l}\text { PROMs were not used proactively. Describes that PROM can provide important information regard patients QoL } \\
\text { during treatment. }\end{array}$ \\
\hline Pearman TP et al. 2018 [54] & $\begin{array}{l}\text { Evaluated the if the use of a single question "I am bothered by side effects of treatment" in different cancer sites } \\
\text { is associated with clinical reported adverse events. PROM were not used proactively. }\end{array}$ \\
\hline Astrup GL et al. 2017 [55] & $\begin{array}{l}\text { Used PROMs to identify patients at risk of developing symptoms during active treatment, but PROMs were not a } \\
\text { part of the FU program. This study was performed on mixed cancer sites. }\end{array}$ \\
\hline Basch E et al. 2016 [56] & $\begin{array}{l}\text { Evaluated the use of PROMs in different cancer sites as a screening tool, for symptom management during } \\
\text { treatment. }\end{array}$ \\
\hline Anderson RT et al. 2019 [57] & PROM were not used proactively but used to predict QoL after cancer diagnosis. \\
\hline Hilarius DL et al. 2008 [58] & $\begin{array}{l}\text { This study was performed on mixed cancer sites. Study excluded because PROMs were collected during } \\
\text { treatment and data on OC patients were not reported separately. }\end{array}$ \\
\hline Shalowitz D. 2015 [59] & Used questionnaires to investigate prognostic issues among clinician. \\
\hline Kew FM et al. 2006 [60] & Aimed to investigate current practice regarding FU of OC patients. PROMs were not used pro-actively. \\
\hline
\end{tabular}

patient-clinician communication with the potential to increase the awareness of patient needs [23]. The majority of participants were breast cancer patients receiving first line palliative chemotherapy. This population represents a group with a poor prognosis. These findings were supported by those from a randomized clinical trial involving 766 patients with solid tumors assessed by PROMs during active cancer treatment. Routine collection of PROM data was associated with improved survival by a median of 5 months, suggesting that proactive monitoring helps the clinician to intervene before symptoms cause complications [12]. The participants were recruited between 2007 and 2011, and they had different metastatic cancer types (mainly genitourinary cancer), with a poor prognosis. Such a long timeframe for enrollment may have involved a change of treatment, which could have impacted on survival and burden of symptoms. However, the patients completing PROMs received chemotherapy for a longer period than those receiving usual care. This illustrates the potential of PROMs to detect otherwise unrecognized symptoms during treatment in order to prevent serious events at a later stage.

Hansen et al. found that cancer patients experienced a variety of unmet needs during treatment but also during follow-up, and highlights that the patients indicated that they did not received the support that they needed during follow-up. Unmet needs have an important influence on QoL and PROMs used as a screening tool may reveal patients' perceived unmet need. Interventions to reduce these unmet needs could enhance patient's quality of life [62]. Ploos van Amstel et al. aimed to explore distress 
and quality of life in ovarian cancer patients' during and after treatment, with a mean time since surgery of 3.3 years. The authors found that a third of the participants' expressed distress. Almost half of the patients with distress indicated that they wanted a referral to a professional [63]. Their findings indicate that ovarian cancer survivors undergo distress and experience symptoms years after they have finished treatment. If PROMs were used proactively during follow-up this could potentially address patients' needs and lead to higher satisfaction and improved QoL.

Velikova et al. found that if PROM results were shared with physicians before the clinical encounter, discussions of symptoms took place more frequently compared with the control group. A third of the patients were diagnosed with gynecologic cancer, and PROMs were primarily used during active treatment. Only 2 (1\%) participants completed PROMs during follow up. It is unclear if they had gynecologic cancer and the findings are not presented separately. This study adds weight to the conclusion that good communication between clinician and patient should be central to the management of cancer patients. Further, the improved communication resulted in better QoL and emotional functioning for some patients [10]. Howell et al. also reported that if the QoL score was shared with the clinician before the consultation, the level of discussion on emotional and psychosocial issues increased [64].

Many studies have investigated the QoL of OC survivors, late side effects, coping strategies, and many other outcomes over time. If PROMs are collected and used actively during treatment, a positive effect on patientclinician communication, improved QoL, and a better symptom management during treatment is described. The current model for FU of OC patients is characterized by pre-scheduled visits and mainly concerns standard procedures without necessarily taking the patients' needs and preferences into account. Pre-scheduled visits may take place at a time when the patient is asymptomatic and thereby induce false reassurance. The value of the standard approach to FU is uncertain, and it is not evidence based. Because of the poor prognosis of OC patients in case of relapse, it is essential to optimize the FU program to focus on what matters most to the patient. Furthermore, pro-active use of PROMs will help ensure that patients are met on their own premises and that the time spent during the consultation is used to help the patient with the problems that bother them the most.

Although interest in collecting PROMs in clinical trials and using them actively as a screening or dialogue tool during treatment is growing, our literature search shows that unfortunately, there is not much experience with this for the benefit of ovarian cancer patients. If PROMs are used proactively during consultations, the visit can be tailored to match the individual patient's preferences and needs. This may be a new approach to routine collection of PROMs to improve patient centered care and individualized treatment.

We are aware of the limitations of this review. Although we used a comprehensive search strategy, it is still possible that some studies may have been missed. Also, data extraction was performed by only one reviewer who made all decisions about inclusion and exclusion. Lastly, it should be noted that any studies published after 14th of April 2019 were not considered in this paper.

\section{Conclusion}

To our knowledge, no studies have used PROMs as a screening or dialogue tool for ovarian cancer survivors during follow-up. The use of PROMs with these patients may help identify otherwise undetected symptoms and improve the management of late side effects. Proactive use of PROMs during follow-up may enhance patient involvement leading to increased satisfaction with care. We believe there is a strong case for further research into this approach to improve the quality of follow-up care of ovarian cancer survivors.

\section{Additional file}

Additional file 1: Seach strategy for databases PubMed, Embase,

CINAHL and The Cochrane Library. (DOCX $21 \mathrm{~kb}$ )

\section{Abbreviations \\ FU: Follow-up; OC: Ovarian Cancer; PROMs: Patient Reported Outcome Measures; QoL: Quality of Life; SCP: Survivorship Care Plan}

\section{Acknowledgements}

We thank Karin Larsen for linguistic editing of the manuscript.

\section{Authors' contributions}

All authors were a major contributor in writing this manuscript, and all have helped identify additional "gray literature". All co-authors has read and approved the final manuscript.

\section{Funding}

As a PhD student Anette Stolberg Kargo received funding from The Danish Cancer Society. The funder played no role in the design in the undertaking of the review or in writing the manuscript.

\section{Availability of data and materials}

All data generated during this study are included in this published article in Table 1 and in supplementary material.

Ethics approval and consent to participate

Not applicable.

Consent for publication

Not applicable.

Competing interests

The authors declare that they have no competing interests. 


\section{Author details}

'Department of Clinical Oncology, Sygehus Lillebalt, Vejle Sygehus, Beriderbakken 4, DK-7100 Vejle, Denmark. Institute of Regional Health Research, University of Southern Denmark, Winsløwparken 19, 3, 5000 Odense, Denmark. ${ }^{3}$ Center for Shared Decision Making, Sygehus Lillebalt, Vejle Sygehus, Beriderbakken 4, 7100 Vejle, Denmark. ${ }^{4}$ Department of Gynaecology and Obstetrics, Odense University Hospital, J. B. Winsløws Vej 4, 5000 Odense, Denmark. ${ }^{5}$ Department of Clinical Research, University of Southern Denmark, Winsløwparken 19, 3, 5000 Odense, Denmark.

\section{Received: 25 November 2018 Accepted: 4 July 2019}

\section{Published online: 15 July 2019}

\section{References}

1. International Agency for Research on Cancer. Global cancer statistics 2012. . Accessed.

2. Rustin GJ, van der Burg ME, Griffin $\mathrm{CL}$, et al. Early versus delayed treatment of relapsed ovarian cancer (MRC OV05/EORTC 55955): a randomised trial. Lancet (London, England). 2010;376(9747):1155-63.

3. Dahl L, Wittrup I, Vaeggemose U, Petersen LK, Blaakaer J. Life after gynecologic cancer--a review of patients quality of life, needs, and preferences in regard to follow-up. Int J Gynecol Cancer. 2013;23(2):227-34.

4. Olesen ML, Hansson H, Ottesen B, Thranov IR, Thisted LB, Zoffmann V. The psychosocial needs of gynaecological cancer survivors: A framework for the development of a complex intervention. Eur J Oncol Nurs. 2015;19(4):349-58.

5. FDA. Guidance for Industry Patient-Reported Outcome Measures. Use in medical product development to support labeling claims. Clin FED Regist. 2009;2009:1-39

6. Coulter A PC, Peters M, Fitzpatrick R. Cancer PROMs: a scoping study. Macmillan Cancer Support; 2015.

7. Lockwood-Rayermann S. Survivorship issues in ovarian cancer: a review. Oncol Nurs Forum. 2006;33(3):553-62

8. Berry DL, Blumenstein BA, Halpenny B, et al. Enhancing patient-provider communication with the electronic self-report assessment for cancer: a randomized trial. J Clin Oncol. 2011;29(8):1029-35.

9. Sepucha KR, Levin CA, Uzogara EE, Barry MJ, O'Connor AM, Mulley AG. Developing instruments to measure the quality of decisions: early results for a set of symptom-driven decisions. Patient Educ Couns. 2008;73(3):504-10.

10. Velikova $G$, Booth $L$, Smith $A B$, et al. Measuring quality of life in routine oncology practice improves communication and patient well-being: a randomized controlled trial. J Clin Oncol. 2004;22(4):714-24.

11. Hess LMP, Stehman FBMD. State of the science in ovarian Cancer quality of life research: A systematic review. Int J Gynecol Cancer. 2012;22(7):1273-80.

12. Basch $E$, Deal $A M$, Dueck $A C$, et al. Overall survival results of a trial assessing patient-reported outcomes for symptom monitoring during routine Cancer treatment. Jama. 2017:318(2):197-8

13. Liberati A, Altman DG, Tetzlaff J, et al. The PRISMA statement for reporting systematic reviews and meta-analyses of studies that evaluate health care interventions: explanation and elaboration. J Clin Epidemiol. 2009;62(10):e1-34.

14. Moher D, Liberati A, Tetzlaff J, Altman DG. Preferred reporting items for systematic reviews and meta-analyses: the PRISMA statement. J Clin Epidemiol. 2009;62(10):1006-12.

15. Hess LM, Stehman FB. State of the science in ovarian cancer quality of life research: a systematic review. Int J Gynecol Cancer. 2012;22(7):1273-80.

16. Hilpert F, Du Bois A. Patient-reported outcomes in ovarian cancer: are they key factors for decision making? Expert Rev Anticancer Ther. 2018;18(sup1):3-7.

17. Wiering B, de Boer D, Delnoij D. Patient involvement in the development of patient-reported outcome measures: a scoping review. Health Expect. 2017; 20(1):11-23.

18. Preston NJ, Wilson N, Wood NJ, Brine J, Ferreira J, Brearley SG. Patientreported outcome measures for use in gynaecological oncology: a systematic review. BJOG. 2015;122(5):615-22.

19. Clarke T, Galaal K, Bryant A, Naik R. Evaluation of follow-up strategies for patients with epithelial ovarian cancer following completion of primary treatment. Cochrane Database Syst Rev. 2014;(9).

20. Kew F, Galaal K, Bryant A, Naik R. Evaluation of follow-up strategies for patients with epithelial ovarian cancer following completion of primary treatment. The Cochrane database of systematic reviews. 2011:(6):Cd006119.

21. Zikos E, Coens C, Quinten C, et al. The added value of analyzing pooled health-related quality of life data: A review of the EORTC PROBE initiative. J Natl Cancer Inst. 2016;108(5).
22. Ahmed-Lecheheb D, Joly F. Ovarian cancer survivors' quality of life: a systematic review. J Cancer Surviv. 2016;10(5):789-801.

23. Detmar SB, Muller MJ, Schornagel JH, Wever LD, Aaronson NK. Healthrelated quality-of-life assessments and patient-physician communication: a randomized controlled trial. Jama. 2002;288(23):3027-34.

24. King MT, Stockler MR, O'Connell RL, et al. Measuring what matters MOST: validation of the measure of ovarian symptoms and treatment, a patientreported outcome measure of symptom burden and impact of chemotherapy in recurrent ovarian cancer. Quality of Life Research: An International Journal of Quality of Life Aspects of Treatment, Care \& Rehabilitation. 2018;27(1):59-74

25. McCorkle R, Jeon S, Ercolano E, Schwartz P. Healthcare utilization in women after abdominal surgery for ovarian cancer. Nurs Res. 2011; 60(1):47-57

26. Meraner V, Gamper EM, Grahmann A, et al. Monitoring physical and psychosocial symptom trajectories in ovarian cancer patients receiving chemotherapy. BMC Cancer. 2012;12:77.

27. Beesley $\mathrm{VL}$, Price MA, Webb PM, et al. Changes in supportive care needs after first-line treatment for ovarian cancer: identifying care priorities and risk factors for future unmet needs. Psycho-oncology. 2013;22(7):1565-71.

28. Stewart DE, Wong F, Duff S, Melancon CH, Cheung AM. "what doesn't kill you makes you stronger": an ovarian cancer survivor survey. Gynecol Oncol. 2001;83(3):537-42

29. Bodurka-Bevers D, Basen-Engquist K, Carmack CL, et al. Depression, anxiety, and quality of life in patients with epithelial ovarian cancer. Gynecol Oncol. 2000:78(3 Pt 1):302-8.

30. Greimel ER, Bjelic-Radisic V, Pfisterer J, et al. Toxicity and quality of life outcomes in ovarian cancer patients participating in randomized controlled trials. Support Care Cancer. 2011;19(9):1421-7.

31. Liavaag AH, Dorum A, Fossa SD, Trope C, Dahl AA. Controlled study of fatigue, quality of life, and somatic and mental morbidity in epithelial ovarian cancer survivors: how lucky are the lucky ones? J Clin Oncol. 2007; 25(15):2049-56

32. Matei $D$, Miller AM, Monahan $P$, et al. Chronic physical effects and health care utilization in long-term ovarian germ cell tumor survivors: a gynecologic oncology group study. J Clin Oncol. 2009;27(25):4142-9.

33. Mercieca-Bebber RL, Price MA, Bell ML, King MT, Webb PM, Butow PN. Ovarian cancer study dropouts had worse health-related quality of life and psychosocial symptoms at baseline and over time. Asia Pac J Clin Oncol. 2017;13(5):e381-8.

34. Guidozzi F. Living with ovarian cancer. Gynecol Oncol. 1993;50(2):202-7.

35. Chase DM, Wenzel L. Health-related quality of life in ovarian cancer patients and its impact on clinical management. Expert Rev Pharmacoecon Outcomes Res. 2011;11(4):421-31.

36. Williams LA, Agarwal S, Bodurka DC, Saleeba AK, Sun CC, Cleeland CS. Capturing the patient's experience: using qualitative methods to develop a measure of patient-reported symptom burden: an example from ovarian cancer. J Pain Symptom Manag. 2013;46(6):837-45

37. Greimel E, Bottomley A, Cull A, et al. An international field study of the reliability and validity of a disease-specific questionnaire module (the QLQOV28) in assessing the quality of life of patients with ovarian cancer. Eur J Cancer. 2003;39(10):1402-8.

38. Snyder CF, Aaronson NK. Use of patient-reported outcomes in clinical practice. Lancet (London, England). 2009;374(9687):369-70.

39. Bordlein-Wahl I, Hilpert F, Kohlmann T. Evaluating treatment from the point of view of the patient -PROs (patient-reported outcomes). Onkologie. 2009; 32(Suppl 1):18-20.

40. Roncolato FT, Gibbs E, Lee CK, et al. Quality of life predicts overall survival in women with platinum-resistant ovarian cancer: an AURELIA substudy. Ann Oncol. 2017:28(8):1849-55.

41. Jensen RE, Snyder CF. PRO-cision medicine: personalizing patient care using patient-reported outcomes. J Clin Oncol. 2016;34(6):527-9.

42. Beesley VL, Smith DD, Nagle CM, et al. Coping strategies, trajectories, and their associations with patient-reported outcomes among women with ovarian cancer. Support Care Cancer. 2018;26(12):4133-42.

43. Du Bois A, Rochon J, Lamparter C, Pfisterer J. Pattern of care and impact of participation in clinical studies on the outcome in ovarian cancer. Int J Gynecol Cancer. 2005;15(2):183-91.

44. Madalinska JB, van Beurden M, Bleiker EM, et al. Predictors of prophylactic bilateral salpingo-oophorectomy compared with gynecologic screening use in BRCA1/2 mutation carriers. J Clin Oncol. 2007;25(3):301-7. 
45. de Rooij BH, Ezendam NPM, Nicolaije KAH, et al. Effects of survivorship care plans on patient reported outcomes in ovarian cancer during 2-year followup - the ROGY care trial. Gynecol Oncol. 2017;145(2):319-28.

46. Phillips KA, Haas JS, Liang SY, et al. Are gatekeeper requirements associated with cancer screening utilization? Health Serv Res. 2004;39(1):153-78.

47. Cesario SK, Nelson LS, Broxson A, Cesario AL. Sword of Damocles cutting through the life stages of women with ovarian cancer. Oncol Nurs Forum. 2010;37(5):609-17.

48. Keim-Malpass J, Mihalko SL, Russell G, Case D, Miller B, Avis NE. Problems experienced by ovarian Cancer survivors during treatment. J Obstet Gynecol Neonatal Nurs. 2017:46(4):544-54

49. Oberguggenberger A, Sztankay M, Morscher RJ, et al. Psychosocial outcomes and counselee satisfaction following genetic counseling for hereditary breast and ovarian cancer: A patient-reported outcome study. J Psychosom Res. 2016:89:39-45.

50. Stukenborg GJ, Blackhall LJ, Harrison JH, Dillon PM, Read PW. Longitudinal patterns of cancer patient reported outcomes in end of life care predict survival. Support Care Cancer. 2016;24(5):2217-24.

51. Rietveld M, Husson O, Vos C, Van De Poll-Franse L, Ottevanger N. Perceived information provision, is it related to supportive care needs? Int J Gynecol Cancer. 2016;26 (Supplement 3:810.

52. Beesley VL, Price MA, Butow PN, Green AC, Olsen CM, Webb PM. Physical activity in women with ovarian cancer and its association with decreased distress and improved quality of life. Psycho-oncology. 2011;20(11):1161-9.

53. Greimel E, Bjelic-Radisic V, Nagele E, Bliem B, Tamussino K. Quality of life in patients with ovarian cancer. [German]. Onkologe. 2019:25(2):151-6.

54. Pearman TP, Beaumont JL, Mroczek D, O'Connor M, Cella D. Validity and usefulness of a single-item measure of patient-reported bother from side effects of cancer therapy. Cancer. 2018;124(5):991-7.

55. Astrup GL, Hofso K, Bjordal K, et al. Patient factors and quality of life outcomes differ among four subgroups of oncology patients based on symptom occurrence. Acta Oncol. 2017;56(3):462-70.

56. Basch E, Deal AM, Kris MG, et al. Symptom monitoring with patient-reported outcomes during routine Cancer treatment: A randomized controlled trial. J Clin Oncol. 2016;34(6):557-65.

57. Anderson RT, Peres LC, Camacho F, et al. Individual, social, and societal correlates of health-related quality of life among African American survivors of ovarian cancer: results from the African American cancer epidemiology study. J Women's Health. 2019;28(2):284-93.

58. Hilarius DL, Kloeg PH, Gundy CM, Aaronson NK. Use of health-related quality-of-life assessments in daily clinical oncology nursing practice: a community hospital-based intervention study. Cancer. 2008;113(3):628-37.

59. Shalowitz DI, Schorge JO. Suggestibility of Oncologists' clinical estimates. JAMA oncology. 2015;1(2):251-3.

60. Kew FM, Cruickshank DJ. Routine follow-up after treatment for a gynecological cancer: a survey of practice. Int J Gynecol Cancer. 2006;16(1): 380-4.

61. Basch $E$, Artz D, Dulko D, et al. Patient online self-reporting of toxicity symptoms during chemotherapy. J Clin Oncol. 2005;23(15):3552-61.

62. Hansen DG, Larsen PV, Holm LV, Rottmann N, Bergholdt SH, Sondergaard J. Association between unmet needs and quality of life of cancer patients: a population-based study. Acta Oncol. 2013;52(2):391-9.

63. Ploos van Amstel FKRNM, van Ham MAPCPMD, Peters EJM, Prins JBPM, Ottevanger PBPMD. Self-reported distress in patients with ovarian Cancer: is it related to disease status? Int J Gynecol Cancer. 2015;25(2):229-35.

64. Howell D, Molloy S, Wilkinson $\mathrm{K}$, et al. Patient-reported outcomes in routine cancer clinical practice: a scoping review of use, impact on health outcomes, and implementation factors. Ann Oncol. 2015;26(9):1846-58.

\section{Publisher's Note}

Springer Nature remains neutral with regard to jurisdictional claims in published maps and institutional affiliations.

Ready to submit your research? Choose BMC and benefit from:

- fast, convenient online submission

- thorough peer review by experienced researchers in your field

- rapid publication on acceptance

- support for research data, including large and complex data types

- gold Open Access which fosters wider collaboration and increased citations

- maximum visibility for your research: over $100 \mathrm{M}$ website views per year

At $\mathrm{BMC}$, research is always in progress.

Learn more biomedcentral.com/submissions 